\title{
Lateral Ankle Sprain: Current Strategies of Management and Rehabilitation Short of Surgery
}

\author{
Sidak Dhillon ${ }^{1}$, Bibek Adhya ${ }^{2}$, Rajesh K Rajnish ${ }^{3}$, Himmat Dhillon ${ }^{4}$, Mandeep S Dhillon ${ }^{5}$
}

\begin{abstract}
Lateral ankle sprain is a common injury in physically active individuals; for purposes of adequate recovery, it is important to clinically grade the severity of ankle sprains, and plan appropriate rehabilitation interventions. The risk of subsequent ankle sprains, chronic ankle pain, and ankle instability is significant, especially in elite athletes. Modern methods of rehabilitation are more aggressive; in addition to the rest, ice, compression, and elevation (RICE) protocols, early phased functional support and supervised exercise therapy are considered better for early recovery. This should include graded neuromuscular and proprioceptive exercises over during the recovery phase. Specialized ankle stability programs need to be considered for professional athletes, with special attention to individual risk factors that could predispose them to recurrent lateral ankle sprains. The management protocol for recurrent sprains, although similar, needs to be more aggressive depending on the extent of the injury, duration since the first injury, and the associated instability. Modern methods include computerized documentation and the use of robots to oversee rehabilitation protocols.
\end{abstract}

Keywords: Ankle rehabilitation, Ankle sprain, Recurrent ankle sprains.

Journal of Foot and Ankle Surgery (Asia Pacific) (2022): 10.5005/jp-journals-10040-1196

\section{BACKGROUND}

Ankle sprain or injury to the passive ligamentous structures on the lateral aspect of the ankle joint, ${ }^{1}$ is commonly caused by forefoot adduction and hindfoot inversion, associated with the external rotation of the tibia, while the ankle joint is in plantar flexion. The lateral ligaments of the ankle are the anterior talofibular ligament (ATFL), the calcaneofibular ligament (CFL), and the posterior talofibular ligament. Depending on the amount and direction of forces, one or more ligaments can be injured, with an ATFL being the most commonly injured (approximately 70\%) as it is the weakest among all. ${ }^{1}$

For the purposes of rehabilitation, it is important to understand the severity of ankle sprains; Grade I-mild ligament stretching without joint instability; Grade II, a partial rupture with mild joint instability; and Grade III being complete rupture of the ligament complex with ankle instability. ${ }^{2}$

\section{Diagnosis}

The clinical examination may show the presence of swelling, ecchymosis, point tenderness, pain full range of motion, or ligamentous laxity depending upon the severity of injury. ${ }^{1,3}$ The presence of hematoma accompanied by tenderness around the distal fibula and/or a positive anterior drawer test are suggestive of ruptured lateral ankle ligaments. The sensitivity (84\%) and the specificity ( $96 \%$ ) of physical examination using the anterior drawer test are optimized if the clinical assessment is delayed for 4-5 days post-injury, ${ }^{4,5}$ as the subsidence of inflammation and pain allows an easier examination.

\section{Management and Rehabilitation}

In the 21st century, the so-called "conservative method of treatment" comprising rest, ice, compression, and elevation (RICE) is being replaced by more aggressive rehabilitation interventions. ${ }^{6}$ The role of NSAIDs in an acute ankle sprain is to reduce pain and swelling; however, their use may be associated with complications
${ }^{1}$ Consultant Sports Physician, Mohali, Punjab, India

${ }^{2}$ Department of Physical and Rehabilitation Medicine, Postgraduate Institute of Medical Education and Research, Chandigarh, India

${ }^{3}$ Department of Orthopaedics, All India Institute of Medical Sciences, Bilaspur, Himachal Pradesh, India

${ }^{4}$ Department of Physiotherapy, SportsHealth Physio, Melbourne, Victoria, Australia

${ }^{5}$ Department of Orthopaedics, Postgraduate Institute of Medical Education and Research, Chandigarh, India

Corresponding Author: Rajesh K Rajnish, Department of Orthopaedics, All India Institute of Medical Sciences, Bilaspur, Himachal Pradesh, India, Phone: +91 9650736850, e-mail: duktiraj@gmail.com

How to cite this article: Dhillon S, Adhya B, Rajnish RK, et al. Lateral Ankle Sprain: Current Strategies of Management and Rehabilitation Short of Surgery. J Foot Ankle Surg (Asia Pacific) 2022;9(1):46-49.

Source of support: Nil

Conflict of interest: None

like delay in the natural process of healing; ${ }^{6}$ thus, NSAIDs should be limited to the initial period of acute distress.

Immobilization strategies have undergone a significant change in the 21st century; the routine use of below-knee cast (sometimes up to 4 weeks) has been shown to have inferior outcomes compared with a protocol of functional support and exercise strategies for the same time period. ${ }^{7,8}$ However, there is some data from recent randomized control trials showing that immobilization in a plaster cast for periods $<10$ days can be beneficial, as it decreases pain and edema and improves functional outcomes. ${ }^{9,10}$

Functional support like ankle braces or tape are found to be more effective when compared with the less adequate support given by compression bandage or by rigidly immobilizing in casts ${ }^{11}$ (Figs 1 and 2).

Exercise therapy is considered to be an integral part of the treatment, which consists of both neuromuscular and 


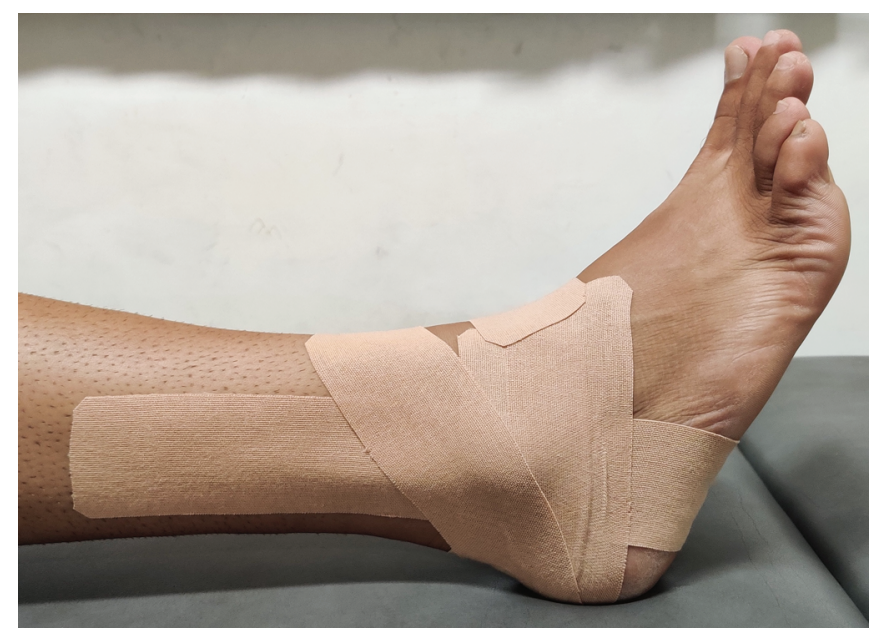

Fig. 1: Kinesiotaping for ankle joint

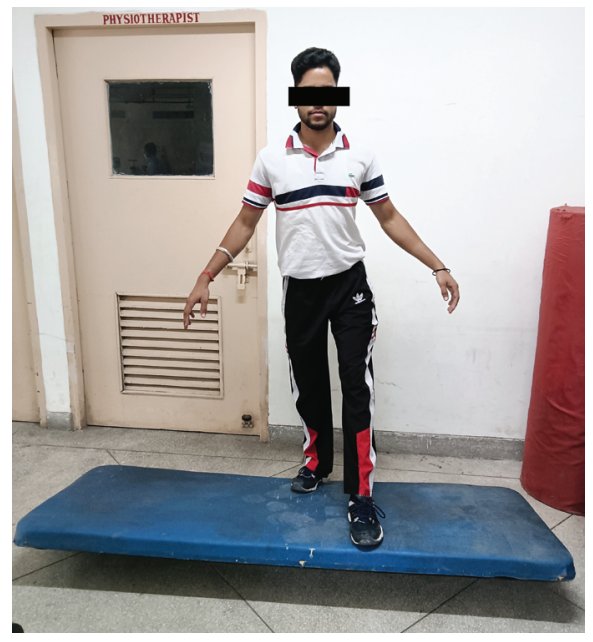

Fig. 3: Proprioception exercise on balance board

proprioceptive exercise (Figs 3 and 4); exercise therapy initiated earlier following an ankle sprain is definitely better. Appropriate rehabilitation can prevent recurrent ankle sprains and future functional ankle instability ${ }^{12-16}$ (Table 1).

\section{Recurrent Ankle Sprains}

The two most common risk factors for recurrent lateral ankle sprain are younger age at injury and the previous history of a lateral ankle sprain. ${ }^{17,18}$ In professional athletes, extra efforts need to be made to identify such individuals and put them through special ankle stability programs depending on their conditions. Some of the risk factors leading to recurrent lateral ankle sprains are inappropriate management of previous sprain, improper treatment program implementation, unrecognized residual ankle instability, biomechanical abnormalities, and muscular imbalance. Other factors can be residual scar tissue and participation in high-risk contact sports.

\section{Protocols for Management of Recurrent Sprains}

Ankle ligaments and soft tissues repaired by scar tissue formation can never be as strong as the original tissue. That is why proper strengthening and proprioception are required to prevent re-injury., ${ }^{1,1920}$

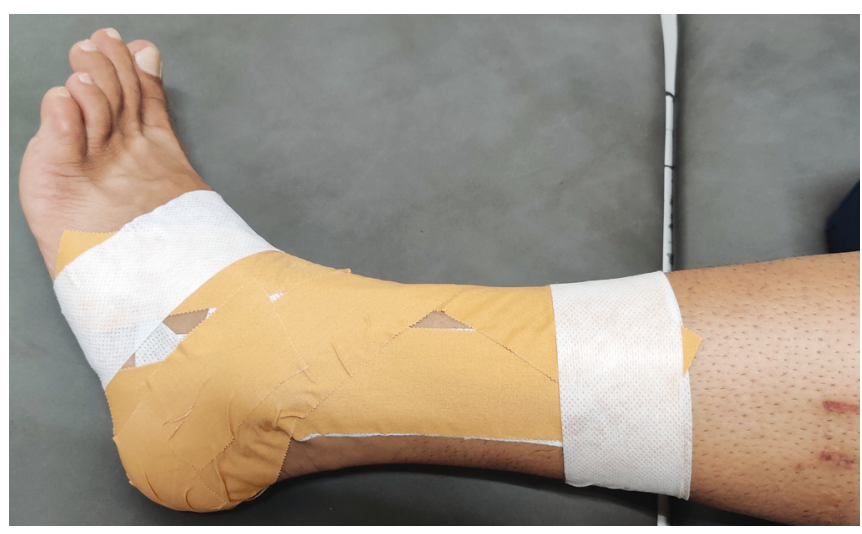

Fig. 2: Rigid sports taping for ankle joint

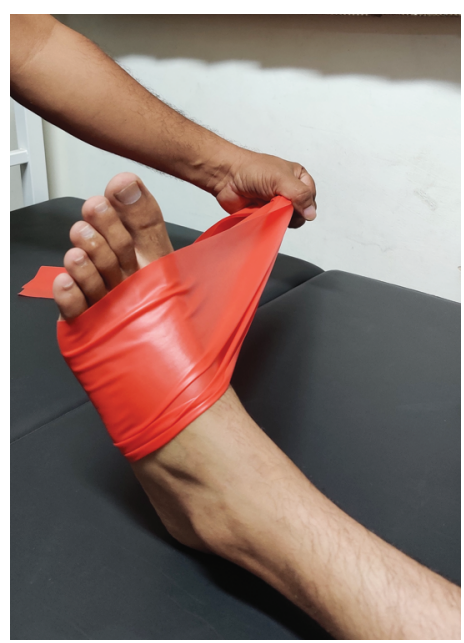

Fig. 4: Strengthening exercise with Theraband, focused on ankle evertors

For the management of re-injury, the same protocol as mentioned in Table 1 can be used; however, it may need to be more aggressive depending on the extent of the injury, duration since the first injury, and the associated instability.

The best option in high-risk groups and elite athletes predisposed to an ankle injury is injury prevention (Table 2).

\section{Return to Normal Activity}

Return to pre-injury activity is the most important outcome of any injury management protocol. It is very difficult to predict the return to normal activity as it is an individualistic approach. The main factors that affect this are the type of injury, type of management, recurrence, and level of activity that the individual is required to return to. In general population return to normal activity is easier when compared with the athletic population. In both cases, functionality needs to be normal along with no pain or residual muscle imbalance. In a recent study done in 2021, a consensus was formed based on multiple factors called the PAASS framework for a return to sport ${ }^{17}$ (Table 3 ). This protocol helps make the return of an athlete back to sporting activity more individualistic and personalized. Along with the functional deficits, cardiovascular fitness also needs to be equal to or greater than the preinjury level. ${ }^{18}$ Therefore, for the general and athletic population, a holistic assessment of the individual is very important before they return 
Table 1: Protocols for rehabilitation of lateral ankle sprain

\begin{tabular}{|c|c|c|}
\hline Phases & Goals & Exercise/Interventions \\
\hline \multirow[t]{8}{*}{ Immediate phase (1-7 days) } & \multirow[t]{4}{*}{ To reduce edema and pain. } & Rest, Ice, Compression, and Elevation (RICE Protocol). \\
\hline & & $\begin{array}{l}\text { Ice application (cryotherapy) 5-6 times/day (around } \\
12-15 \text { minutes). }\end{array}$ \\
\hline & & Interferential therapy or TENS to reduce pain at this stage. \\
\hline & & Ultrasound therapy may also help with the pain. \\
\hline & \multirow[t]{2}{*}{ To protect ligaments and other soft tissues. } & $\begin{array}{l}\text { Compression bandage to reduce edema. Taping to control } \\
\text { edema and promote lymphatic drainage. }\end{array}$ \\
\hline & & Weight-bearing as tolerated. \\
\hline & \multirow[t]{2}{*}{$\begin{array}{l}\text { To maintain knee, MTP, and IP joint } \\
\text { movement. }\end{array}$} & $\begin{array}{l}\text { In the athletic population, weight-bearing is encouraged and } \\
\text { functional braces or tapes protect against excessive inversion } \\
\text { and eversion movements. }\end{array}$ \\
\hline & & $\begin{array}{l}\text { Trigger point release for calf muscles and peronei muscles. } \\
\text { Isometric and ROM exercises for knee, MTP, and IP joints. }\end{array}$ \\
\hline \multirow[t]{8}{*}{ Early phase ( $2-4$ weeks) } & To reduce pain and swelling. & Continue all steps from the previous phase. \\
\hline & \multirow[t]{2}{*}{ To promote healing. } & $\begin{array}{l}\text { Low-level laser therapy increases blood flow and helps } \\
\text { promote healing. }\end{array}$ \\
\hline & & Gentle pain-free friction massage also promotes healing. \\
\hline & \multirow[t]{5}{*}{ To gradually load the muscles. } & $\begin{array}{l}\text { Talocrural glides and talocrural distraction increase joint } \\
\text { mobility. }\end{array}$ \\
\hline & & Plantar fascia stretching. \\
\hline & & Towel crunch/gathering exercise. \\
\hline & & $\begin{array}{l}\text { Dynamic Concentric and Eccentric exercise for Dorsiflexors, } \\
\text { Invertors (esp. Tibialis Posterior), Evertors (Peroneus Longus } \\
\text { and Brevis), Plantar flexors. }\end{array}$ \\
\hline & & Seated calf raises and standing calf raises as tolerated. \\
\hline \multirow[t]{10}{*}{ Intermediate phase (4-6 weeks) } & \multirow[t]{4}{*}{ To increase muscle loading } & $\begin{array}{l}\text { Progressive dorsiflexion and plantar flexion exercises with } \\
\text { resistance bands. }\end{array}$ \\
\hline & & Quadriceps strengthening exercises. \\
\hline & & Hamstring strengthening exercises. \\
\hline & & Gradually increase resistance. \\
\hline & \multirow[t]{4}{*}{ To start proprioception training. } & Single leg balancing on a flat surface. \\
\hline & & $\begin{array}{l}\text { Single leg balancing while throwing and catching an object } \\
\text { on a flat surface. }\end{array}$ \\
\hline & & Single leg balancing with forwarding bending. \\
\hline & & Balance on wobble board, balance ball, and mini-trampoline. \\
\hline & \multirow[t]{2}{*}{ To further progress proprioception training. } & Figure of " 8 " and "Z" walking. \\
\hline & & Tiptoe walking. \\
\hline \multirow[t]{7}{*}{ Late phase ( 6 weeks onward) } & \multirow[t]{7}{*}{ To return to normal activity. } & Continue all steps from the previous phase. \\
\hline & & Start jogging. \\
\hline & & Figure of " 8 " and "Z" walking and jogging. \\
\hline & & Sidestepping and Carioca. \\
\hline & & Progressive running. \\
\hline & & $\begin{array}{l}\text { Balance on wobble board, balance ball, and mini-trampoline } \\
\text { against resistance. }\end{array}$ \\
\hline & & Sports-specific training under supervision. \\
\hline
\end{tabular}

to pre-injury activity levels. In elite athletes, grade III ankle sprains may be surgically managed to minimize the loss of game time.

\section{Newer Developments in Lateral Ankle Sprain Management}

Recent publications ${ }^{21}$ have "discussed Platform-based Robot Designs for Ankle Rehabilitation", using a high-performance training protocol where a robot is used for the ankle rehab; these systems use torque sensing devices and apply the already available exercise and balance protocols. Although in the development phase, these robots are designed to assist patients when their passive motions become limited.

When the ankle sprains become chronic, deficient sensory input from damaged ankle ligament receptors contributes to sensorimotor deficits and influences the overall outcomes and re-injury rates. Sensory-targeted ankle rehabilitation strategy (STARS) is a unique protocol that includes multiple sessions of ankle joint mobilization, plantar massage, and calf stretching. ${ }^{22}$ 
Table 2: Protocols for prevention of ankle sprain

\begin{tabular}{ll}
\hline Goals & Intervention \\
\hline Examination & First step is to examine the individual \\
for any residual damage. & Biomechanical or postural abnormali- \\
& ties need to be found and corrected. \\
& Proper warm-up and cool down \\
Strengthening exercise & Warm-up: active and dynamic \\
& stretching of calf, peronei, and \\
& invertors of ankle along with \\
& hamstring and quadriceps muscles, \\
& followed by sports-specific \\
& movements. \\
& Cool down: passive and static stretch- \\
& ing of the muscles along with foam \\
rolling and occasionally cryotherapy. & Incorporation of foot and ankle \\
Protection & strengthening exercises. \\
& Proprioception, balance, and agility \\
& training. \\
& Taping for support if necessary. \\
& Use of appropriate footwear. \\
&
\end{tabular}

Table 3: PAASS framework for return to sport ${ }^{17}$

\begin{tabular}{ll}
\hline Pain & $\begin{array}{l}\text { During activity or over the last 24 hours. } \\
\text { Decreased range of motion, muscle } \\
\text { strength, endurance, or power. }\end{array}$ \\
Athlete perception & $\begin{array}{l}\text { Self-confidence to get back to activity. } \\
\text { Sensorimotor control }\end{array}$ \\
$\begin{array}{l}\text { Proprioception, postural control, and } \\
\text { balance. }\end{array}$ \\
Sport performance & $\begin{array}{l}\text { Sports-specific drills, hopping, jumping, } \\
\text { and ability to complete a full training } \\
\text { session }\end{array}$ \\
\hline
\end{tabular}

Improvements in weight-bearing lunge test and single-limb balance are significant with individual interventions, but a combination of all three seems to benefit cases with chronic instability.

\section{Take-home Message}

The common ankle sprains may not be innocuous in high-demand individuals. Treatment decisions must be made on an individual case-to-case basis, and most cases do well with a structured rehabilitation protocol. In elite athletes or those with significant functional instability, surgical treatment may be preferred to ensure early return to sports and function. The rehabilitation protocols have evolved in the 21st century, with more aggressive and scientific protocols in place. Injury prevention is as important as injury management, and preventive measures should be incorporated along with training, with or without a previous history of an ankle injury.

\section{RefERENCES}

1. Fong DT, Hong Y, Chan LK, et al. A systematic review on ankle injury and ankle sprain in sports. Sports Med 2007;37(1):73-94. DOI: 10.2165/00007256-200737010-00006.

2. Martin RL, Davenport TE, Paulseth $\mathrm{S}$, et al. Orthopaedic section American Physical Therapy Association. Ankle stability and movement coordination impairments: ankle ligament sprains. J Orthop Sports Phys Ther 2013;43(9):A1-A40. DOI: 10.2519/ jospt.2013.0305.
3. Konradsen L, Hølmer P, Søndergaard L. Early mobilizing treatment for grade III ankle ligament injuries. Foot Ankle 1991;12(2):69-73. DOI: 10.1177/107110079101200202.

4. Malliaropoulos N, Papacostas E, Papalada A, et al. Acute lateral ankle sprains in track and field athletes: an expanded classification. Foot Ankle Clin 2006;11(3):497-507. DOI: 10.1016/j.fcl.2006.05.004.

5. van Dijk CN, Lim LSL, Bossuyt PMM, et al. Physical examination is sufficient for the diagnosis of sprained ankles. J Bone Joint Surg $\mathrm{Br}$ 1996;78(6):958-962. DOI: 10.1302/0301-620x78b6.1283.

6. Polzer H, Kanz KG, Prall WC, et al. Diagnosis and treatment of acute ankle injuries: development of an evidence-based algorithm. Orthop Rev 2012;4(1):5. DOI: 10.4081/or.2012.e5.

7. Vuurberg G, Hoorntje A, Wink LM, et al. Diagnosis, treatment and prevention of ankle sprains: update of an evidence-based clinical guideline. Br J Sports Med 2018;52(15):956. DOI: 10.1136/ bjsports-2017-098106.

8. Kerkhoffs GM, Rowe BH, Assendelft WJ, et al. Immobilisation and functional treatment for acute lateral ankle ligament injuries in adults. Cochrane Database System Rev 2002;3(3):CD003762. DOI: 10.1002/14651858.CD003762.

9. Naeem M, Rahimnajjad MK, Rahimnajjad NA, et al. Assessment of functional treatment versus plaster of paris in the treatment of grade 1 and 2 lateral ankle sprains. J Orthop Traumatol 2015;16(1):41-46. DOI: 10.1007/s10195-014-0289-8.

10. Uslu M, Inanmaz ME, Ozsahin M, et al. Cohesive taping and short-leg casting in acute low-type ankle sprains in physically active patients. J Am Podiatr Med Assoc 2015;105(4):307-312. DOI: 10.7547/13-130.1.

11. Lamb SE, Marsh JL, Hutton JL, et al. Mechanical supports for acute, severe ankle sprain: a pragmatic, multicentre, randomised controlled trial. Lancet 2009;373(9663):575-581. DOI: 10.1016/S01406736(09)60206-3.

12. Prado MP, Mendes AAM, Amodio DT, et al. A comparative, prospective, and randomized study of two conservative treatment protocols for first-episode lateral ankle ligament injuries. Foot Ankle Int 2014;35(3):201-206. DOI: 10.1177/1071100713519776.

13. Rivera MJ, Winkelmann ZK, Powden CJ, et al. Proprioceptive training for the prevention of ankle sprains: an evidence-based review. J Athl Train 2017;52(11):1065-1067. DOI: 10.4085/1062-6050-52.11.16.

14. Zech A, Hübscher M, Vogt $L$, et al. Neuromuscular training for rehabilitation of sports injuries: a systematic review. Med Sci Sports Exerc 2009;41(10):1831-1841. DOI: 10.1249/MSS.0b013e3181a3cf0d.

15. Postle K, Pak D, Smith TO. Effectiveness of proprioceptive exercises for ankle ligament injury in adults: a systematic literature and meta-analysis. Man Ther 2012;17(4):285-291. DOI: 10.1016/j. math.2012.02.016.

16. Petersen W, Rembitzki IV, Koppenburg AG, et al. Treatment of acute ankle ligament injuries: a systematic review. Arch Orthop Trauma Surg 2013;133(8):1129-1141. DOI: 10.1007/s00402-013-1742-5.

17. Smith MD, Vicenzino $B, B a h r R$, et al. Return to sport decisions after an acute lateral ankle sprain injury: introducing the PAASS frameworkan international multidisciplinary consensus. Br J Sports Med 2021. DOI: 10.1136/bjsports-2021-104087bjsports-2021-104087.

18. D'Hooghe P, Cruz F, Alkhelaifi K. Return to play after a lateral ligament ankle sprain. Curr Rev Musculoskele Med 2020;13(3):281-288. DOI: 10.1007/s12178-020-09631-1.

19. Pourkazemi F, Hiller C, Raymond J, et al. Predictors of recurrent sprains after an index lateral ankle sprain: a longitudinal study. Physiotherapy 2018;104(4):430-437. DOI: 10.1016/j.physio.2017.10.004.

20. Brinkman R, Evans T. History of ankle sprain as a risk factor of future lateral ankle sprain in athletes. J Sport Rehabilitat 2011;20(3):384-388. DOI: 10.1123/jsr.20.3.384.

21. Miao Q, Zhang M, Wang C, et al. Towards optimal platformbased robot design for ankle rehabilitation: the state of the art and future prospects. J Healthc Eng 2018;2018:1534247. DOI: 10.1155/2018/1534247.

22. McKeon PO, Wikstrom EA. Sensory-targeted ankle rehabilitation strategies for chronic ankle instability. Med Sci Sports Exerc 2016;48(5):776-784. DOI: 10.1249/MSS.0000000000000859. 